\title{
Combined effects of asbestos and cigarette smoke on the development of lung adenocarcinoma: Different carcinogens may cause different genomic changes
}

\author{
KENTARO INAMURA ${ }^{1}$, HIRONORI NINOMIYA ${ }^{1}$, KIMIE NOMURA ${ }^{1}$, EIJU TSUCHIYA ${ }^{1}$, YUKITOSHI SATOH ${ }^{2}$, \\ SAKAE OKUMURA $^{3}$, KEN NAKAGAWA $^{3}$, AYAKO TAKATA $^{4}$, NORIHIKO KOHYAMA ${ }^{5}$ and YUICHI ISHIKAWA ${ }^{1}$ \\ ${ }^{1}$ Division of Pathology, The Cancer Institute, Japanese Foundation for Cancer Research (JFCR), Koto-ku, Tokyo 135-8550; \\ ${ }^{2}$ Department of Thoracic Surgery, Kitasato University School of Medicine, Sagamihara, Kanagawa 228-8555; \\ ${ }^{3}$ Department of Thoracic Surgery, The Cancer Institute Hospital, JFCR, Koto-ku, Tokyo 135-8550; \\ ${ }^{4}$ Department of Preventive Medicine, St. Marianna University School of Medicine, Miyamae-ku, Kawasaki, \\ Kanagawa 216-8511; ${ }^{5}$ Faculty of Economics, Toyo University, Bunkyo-ku, Tokyo 12-8608, Japan
}

Received February 1, 2014; Accepted April 15, 2014

DOI: $10.3892 /$ or.2014.3263

\begin{abstract}
The carcinogens in cigarette smoke are distinct from asbestos. However, an understanding of their differential effects on lung adenocarcinoma development remains elusive. We investigated loss of heterozygosity $(\mathrm{LOH})$ and the $p 53$ mutation in 132 lung adenocarcinomas, for which asbestos body burden (AB; in numbers per gram of dry lung) was measured using adjacent normal lung. All cases were classified into 9 groups based on a matrix of cumulative smoking (CS in pack-years; $\mathrm{CS}=0,0<\mathrm{CS}<25, \geq 25 \mathrm{CS})$ and $\mathrm{AB}(\mathrm{AB}=0,0<\mathrm{AB}<1,000$, $\geq 1,000 \mathrm{AB}) . \mathrm{AB}=0$ indicates a lower level than the detection limit of $\sim 100$. LOH frequency increased only slightly with the elevation of $\mathrm{CS}$ in the $\mathrm{AB}=0$ groups. In the $\mathrm{AB}>0$ groups, $\mathrm{LOH}$ frequency increased as $\mathrm{AB}$ and/or $\mathrm{CS}$ was elevated and was significantly higher in the $\geq 1,000 \mathrm{AB}, \geq 25 \mathrm{CS}$ group $(\mathrm{p}=0.032)$. p53 mutation frequency was the lowest in the $\mathrm{AB}=0, \mathrm{CS}=0$ group, increased as $\mathrm{AB}$ and/or CS rose, and was significantly higher in the $\geq 1,000 \mathrm{AB}, \geq 25 \mathrm{CS}$ group ( $\mathrm{p}=0.039$ ). p53 mutations characteristic of smoking were frequently observed in the $\mathrm{CS}>0$ groups contrary to non-specific mutations in the $\mathrm{CS}=0$, $\mathrm{AB}>0$ groups. Combined effects of asbestos and smoking were suggested by $\mathrm{LOH}$ and $p 53$ analyses. Sole exposure to asbestos did not increase LOH frequency but increased non-specific $p 53$ mutations. These findings indicate that the major carcinogenic mechanism of asbestos may be tumor promotion, acting in an additive or synergistic manner, contributing to the genotoxic
\end{abstract}

Correspondence to: Dr Yuichi Ishikawa, Division of Pathology, The Cancer Institute, Japanese Foundation for Cancer Research (JFCR), 3-8-31 Ariake, Koto-ku, Tokyo 135-8550, Japan

E-mail: ishikawa@jfcr.or.jp

Key words: lung cancer, asbestos, smoking, loss of heterozygosity, p53 mutation effect of smoking. Since this study was based on a general cancer center's experience, the limited sample size did not permit the consideration that the result was conclusive. Further investigation with a large sample size is needed to establish the mechanism of asbestos-induced lung carcinogenesis.

\section{Introduction}

Lung cancer is one of the leading causes of cancer-related death in both men and women worldwide, and adenocarcinoma is the most predominant histologic subtype in many parts of the world. Tobacco smoke is clearly the most important factor associated with the development of lung cancer, accounting for $80-90 \%$ of all cases. Asbestos is another significant inhaled carcinogen, contributing to the development of $\sim 5-7 \%$ of all lung cancers (1). Many studies on asbestos-related lung carcinogenesis have analyzed the genotoxic effects of asbestos; asbestos fibers induce DNA damage, chromosome aberrations, mitotic disturbances and gene mutations (2). In addition, asbestos fibers can stimulate a range of other effects including cell proliferation, chronic inflammation, enhanced gene expression, such as c-fos and c-jun overexpression, and transformation $(3,4)$. Despite these studies, the efficacy of asbestos-exposure as a complete lung carcinogen, independent of tobacco smoke, has not been demonstrated in humans, since lung cancers of asbestos-exposed individuals frequently occur in smokers and ex-smokers. The majority of asbestos-related lung cancers may result from the combined effects of asbestos and carcinogens in tobacco smoke, with the possibility of a synergistic relationship first proposed by Doll (5). Hence, the mechanism of asbestos-induced lung carcinogenesis still remains unclear.

Both loss of heterozygosity ( $\mathrm{LOH})$ and the $p 53$ mutation are genetic alterations. $\mathrm{LOH}$ is frequently noted in cancer cells and is thought to occur through genetic instability at the chromosomal level. On the other hand, the $p 53$ mutation is a genetic alteration at the nucleotide level. Mutation in the $p 53$ tumor suppressor gene is the most frequently observed gene 
mutation in cancers. As described below, not only p53 mutations but also LOH spectra differ in different cancer types associated with different etiologies. Previously we compared the frequency of $\mathrm{LOH}$ on all autosomal chromosomes among non-small cell lung carcinomas $(6,7)$ as well as $p 53$ mutation patterns with adenocarcinoma cell morphology (8). The frequency of allelic loss on many chromosomal arms was commonly higher in squamous cell carcinomas than in adenocarcinomas. This result suggested that more cumulative genetic changes are associated with tumorigenesis in squamous cell carcinomas than contribute to adenocarcinomas, a pattern which may reflect a difference in the carcinogenic mechanisms responsible for the two histologies. In addition, we observed high frequencies of allelic losses on chromosomes $9 p, 9 q$ and $13 q$ in squamous cell carcinomas, the majority of which were from smokers, and higher frequencies of allelic losses on these arms in adenocarcinomas from smokers than those from non-smokers. This loss of specific chromosomes associated with a particular histology is an example of LOH spectra reflecting etiology. The p53 mutational spectra differ among cancers of various organs, and its frequency and mutational spectra can be said to reflect carcinogenic patterns characteristic of exogenous or endogenous factors and thus may be helpful for identification of the responsible agents, including, among others, cigarette smoke, aflatoxin B1 and ultraviolet light. Hence, the analysis of p53 mutation can provide clues to the etiology of diverse tumors and to the function of specific regions of p53 $(9,10)$. The mutation pattern in smokers shows an excess of $\mathrm{G}: \mathrm{C}$ to $\mathrm{T}$ :A transversions (34.2\%), which are relatively uncommon in non-smokers or passive-smokers (16.6\%) (11). These transversions often occur at codons 157, 158, 245, 248 and 273 , experimentally identified as sites of adduct formation by benzo(a)pyrene, a single polycyclic aromatic hydrocarbon (PAH)-compound found in cigarette smoke. Other PAH-compounds also have a similar preference for adduct formation in these $p 53$ codons $(12,13)$.

In the present study, to elucidate the combined effects of asbestos-exposure and smoking on development of lung adenocarcinomas, we used 132 lung adenocarcinomas, for which we already obtained all detailed smoking histories, comprehensive LOH data for all autosomal chromosomes (7), and p53 mutation data.

\section{Materials and methods}

Patients and sample preparation. A total of 335 cases of lung adenocarcinoma were surgically removed at the Cancer Institute Hospital (CIH), Tokyo, Japan, between September 1989 and August 1996. Among the cases, fresh tumor tissues and corresponding normal lung and detailed smoking histories were successfully collected from 132 patients, which were used as materials in this study. Hence, they were collected semi-randomly without respect to asbestos-exposure status, and therefore provided a representative population for a cancer center in Japan. The clinicopathological data for these samples are summarized in Table I. We used a differentiation grading that was basically according to the former version of the Japanese Lung Cancer Society (14), as previously performed (15). Smoking history was surveyed intensively
Table I. Clinicopathological data of the patients with lung adenocarcinomas analyzed in this study $(n=132)$.

\begin{tabular}{|c|c|}
\hline Clinicopathological features & No. of patients $(\%)$ \\
\hline Age $($ years $\pm S D)$ & $61 \pm 11$ \\
\hline \multicolumn{2}{|l|}{ Gender } \\
\hline Male & $74(56)$ \\
\hline Female & $58(44)$ \\
\hline \multicolumn{2}{|l|}{ Cumulative smoking } \\
\hline $\mathrm{CS}=0$ & $54(41)$ \\
\hline $0<\mathrm{CS}<25$ & $18(14)$ \\
\hline$\geq 25 \mathrm{CS}$ & $60(45)$ \\
\hline \multicolumn{2}{|l|}{ Asbestos burden } \\
\hline $\mathrm{AB}=0$ & $64(48)$ \\
\hline $0<\mathrm{AB}<1,000$ & $28(21)$ \\
\hline$\geq 1,000 \mathrm{AB}<5,000$ & $36(27)$ \\
\hline$\geq 5,000 \mathrm{AB}$ & $4(3)$ \\
\hline \multicolumn{2}{|l|}{ pStage } \\
\hline I & $63(48)$ \\
\hline II-IV & $69(52)$ \\
\hline \multicolumn{2}{|l|}{ Differentiation } \\
\hline Well & $35(27)$ \\
\hline Moderately & $69(52)$ \\
\hline Poorly & $28(21)$ \\
\hline \multicolumn{2}{|l|}{ Size $(\mathrm{mm})$} \\
\hline$<30$ & $75(57)$ \\
\hline$\geq 30$ & $57(43)$ \\
\hline
\end{tabular}

$\mathrm{CS}$, cumulative smoking in pack-years; $\mathrm{AB}$, asbestos burden; pStage, pathological stage. Percentages may not total 100 , due to rounding.

from patients and their families and presented as cumulative smoking (CS) in pack-years. The study protocol was approved by IRB of $\mathrm{CIH}$ and informed consent was obtained from all patients.

Measurement of asbestos-exposure. Asbestos-body burden (AB; in numbers per gram of dry lung tissue) was measured using paraffin blocks of corresponding normal lung tissues by a polarizing microscope (16). The detection limit, which means no $\mathrm{AB}$ was found on the measuring filter sample, was $\sim 100 \mathrm{AB} / \mathrm{g}$ (dry lung) and expressed as 0 in this study.

A matrix of smoking-exposure and asbestos-exposure. To examine the dose-effect relationship of asbestos-exposure (presented as AB) and smoking-exposure (presented as CS in pack-years) on lung adenocarcinomas, we classified all cases into 9 groups based on a matrix of CS in pack-years: $\mathrm{CS}=0$ $(\mathrm{n}=54,41 \%), 0<\mathrm{CS}<25(\mathrm{n}=18,14 \%), \geq 25 \mathrm{CS}(\mathrm{n}=60,45 \%)$, and AB: $A B=0(n=64,48 \%), 0<A B<1,000(n=28,21 \%), \geq 1,000$ AB $(n=40,31 \%)$. Since the patients were selected consecutively from surgical tumor files in a general cancer center, only 4 cases $(3.0 \%)$ exceeded 5,000 in AB. To investigate the mechanism of asbestos-induced lung carcinogenesis in 
A

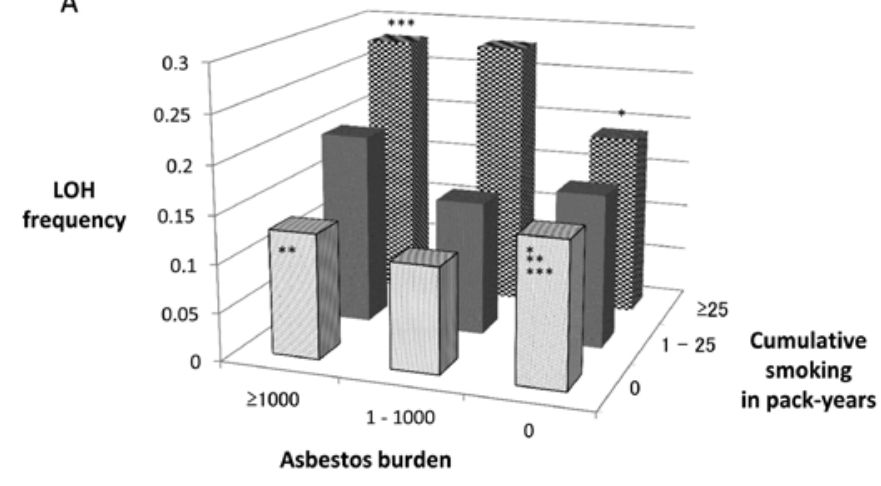

B

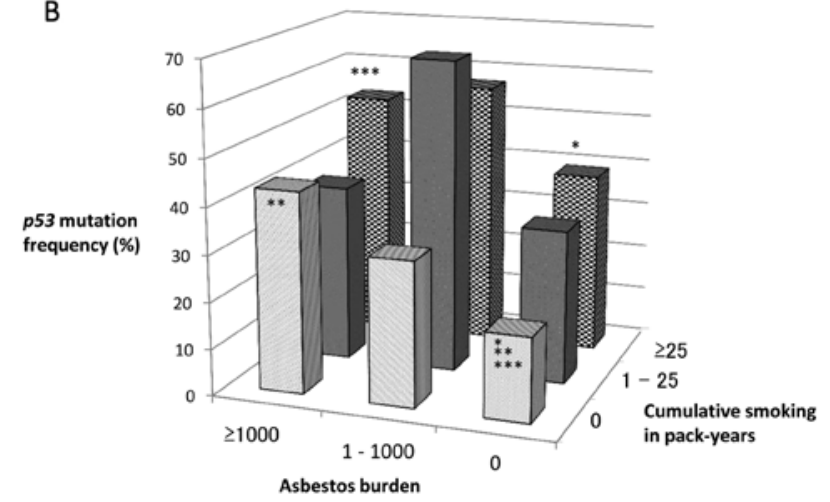

Figure 1. (A) Frequency of the loss of heterozygosity $(\mathrm{LOH})$ in lung adenocarcinomas classified by cumulative smoking $(\mathrm{CS})$ in pack-years $(\mathrm{CS}=0,0<\mathrm{CS}<25$, $\geq 25 \mathrm{CS}$ ) and asbestos burden (AB) $(\mathrm{AB}=0,0<\mathrm{AB}<1,000, \geq 1,000 \mathrm{AB})$. FAL, fractional allelic loss. ${ }^{*} \mathrm{p}=0.30(\mathrm{AB}=0, \mathrm{CS}=0$ vs. $\mathrm{AB}=0,25 \leq \mathrm{CS}) ;{ }^{* *} \mathrm{p}=0.69$ $(\mathrm{AB}=0, \mathrm{CS}=0$ vs. $\geq 1,000 \mathrm{AB}, \mathrm{CS}=0) ;{ }^{* * *} \mathrm{p}=0.032(\mathrm{AB}=0, \mathrm{CS}=0$ vs. $\geq 1,000 \mathrm{AB}, \geq 25 \mathrm{CS})$. (B) $\mathrm{p} 53$ mutation frequency in lung adenocarcinomas classified by $\mathrm{CS}$ in pack-years $(\mathrm{CS}=0,0<\mathrm{CS}<25,25 \leq \mathrm{CS})$ and $\mathrm{AB}(\mathrm{AB}=0,0<\mathrm{AB}<1,000,1,000 \leq \mathrm{AB}){ }^{*} \mathrm{p}=0.14(\mathrm{AB}=0, \mathrm{CS}=0 \mathrm{vs} . \mathrm{AB}=0,25 \leq \mathrm{CS}){ }^{* *} \mathrm{p}=0.14(\mathrm{AB}=0, \mathrm{CS}=0 \mathrm{vs}$. $\geq 1,000 \mathrm{AB}, \mathrm{CS}=0) ;{ }^{* * *} \mathrm{p}=0.039(\mathrm{AB}=0, \mathrm{CS}=0$ vs. $\geq 1,000 \mathrm{AB}, \geq 25 \mathrm{CS})$.

Table II. FAL values ( \pm SD) in lung adenocarcinomas, classified by AB and CS in pack-years.

\begin{tabular}{lllll}
\hline & \multicolumn{4}{c}{$\mathrm{AB}$} \\
\cline { 2 - 4 } & \multicolumn{1}{c}{0} & \multicolumn{1}{c}{$1-1,000$} & \multicolumn{1}{c}{ Total } \\
\hline $\mathrm{CS}$ & & & \\
0 & $0.15( \pm 0.13)(\mathrm{n}=20)$ & $0.11( \pm 0.13)(\mathrm{n}=16)$ & $0.13( \pm 0.16)(\mathrm{n}=13)$ & $0.13( \pm 0.12)(\mathrm{n}=49)$ \\
$1-25$ & $0.16( \pm 0.17)(\mathrm{n}=4)$ & $0.14( \pm 0.04)(\mathrm{n}=3)$ & $0.20( \pm 0.20)(\mathrm{n}=7)$ & $0.18( \pm 0.15)(\mathrm{n}=14)$ \\
$\geq 25$ & $0.19( \pm 0.14)(\mathrm{n}=28)$ & $0.28( \pm 0.25)(\mathrm{n}=6)$ & $0.28( \pm 0.22)(\mathrm{n}=17)$ & $0.23( \pm 0.17)(\mathrm{n}=51)$ \\
Total & $0.17( \pm 0.12)(\mathrm{n}=52)$ & $0.15( \pm 0.16)(\mathrm{n}=25)$ & $0.21( \pm 0.18)(\mathrm{n}=37)$ & $0.18( \pm 0.15)(\mathrm{n}=114)$ \\
\hline
\end{tabular}

FAL, fractional allelic loss; $\mathrm{AB}$, asbestos burden; CS, cumulative smoking.

a representative population for a cancer center, not a biased population heavily exposed to asbestos, we divided the cases between $\mathrm{AB}<1,000$ and $\geq 1,000 \mathrm{AB}$.

LOH analysis. For LOH analysis, we performed Southern blotting. Experimental procedures and probes used were essentially the same as previously described $(6,7)$. To facilitate the comparison, we used a fractional allelic loss (FAL) value, defined as: (number of chromosome arms with $\mathrm{LOH}$ )/(number of informative arms) for each case. Of 132 patients with adenocarcinomas, $\mathrm{LOH}$ data were available for 114 patients.

p53 mutation analysis. Analysis of p53 mutation was performed essentially as described elsewhere (8). Genomic DNA from fresh tumor samples was prepared and exons 4-8 and 10 of $p 53$ were analyzed by polymerase chain reaction and DNA sequencing. Of the 132 patients with adenocarcinomas, p53 mutation data were available for 123 patients.

Statistical analysis. For statistical analysis, we used the t-test, Fisher's exact test, and Chi-square test, as appropriate. The twosided significant level was set at $\mathrm{p}<0.05$. Data were analyzed with the statistical software Stata version 11 (StataCorp., College Station, TX, USA).

\section{Results}

LOH frequency of lung adenocarcinomas classified by CS and $\mathrm{AB}$ is shown in Table II and Fig. 1A. LOH frequency increased only slightly correlating with the elevation of $C S$ in the $A B=0$ groups, whereas, in the $\mathrm{AB}>0$ groups, it increased as $\mathrm{AB}$ and/ or CS was elevated and was significantly higher in the $\geq 1,000$ $\mathrm{AB}, \geq 25 \mathrm{CS}$ group than in the $\mathrm{AB}=\mathrm{CS}=0$ group $(\mathrm{p}=0.032)$.

Details of cases with $p 53$ mutations in lung adenocarcinomas are shown in Table III and summarized in Table IV. The $p 53$ mutation rates of pathological stage I and II-IV lung adenocarcinomas were $32 \%$ (18 of 57) and 44\% (29 of 66), respectively, not significantly different by Fisher's exact test $(\mathrm{p}=0.19)$. p53 mutation frequency of lung adenocarcinomas classified by $\mathrm{CS}$ and $\mathrm{AB}$ are depicted in Fig. 1B. p53 mutation frequency was the lowest in the $\mathrm{AB}=\mathrm{CS}=0$ group (18\%), increased as $\mathrm{AB}$ and/or $\mathrm{CS}$ rose, and was significantly higher in the $\geq 1,000 \mathrm{AB}, \geq 25 \mathrm{CS}$ group (53\%) than in the $\mathrm{AB}=\mathrm{CS}=0$ group ( $\mathrm{p}=0.039$ ). Tobacco smoke, one of the most significant exogenous carcinogenic agents has been shown to frequently cause specific $p 53$ mutations, especially G:C to T:A transversion (17) at specific codons described as 'hotspots', such as codon 157, 158, 245, 248 and 273 (13). p53 mutations characteristic of smoking, such as G:C to T:A transversion at the 


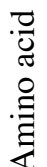

สิ

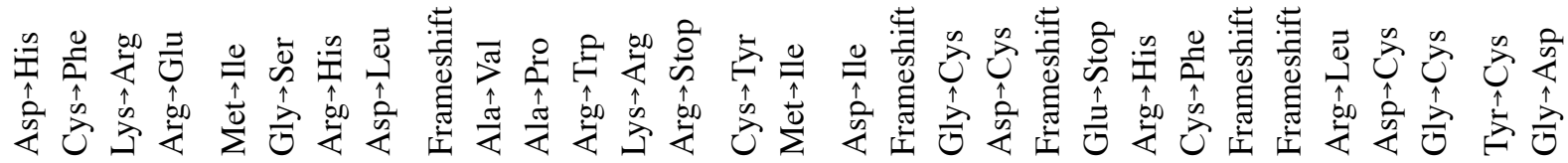

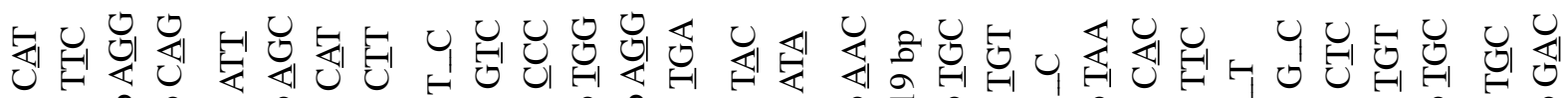

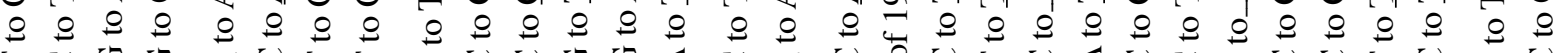

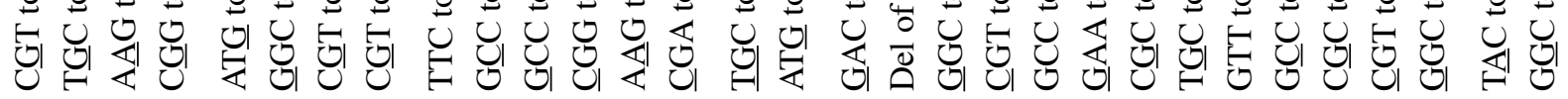

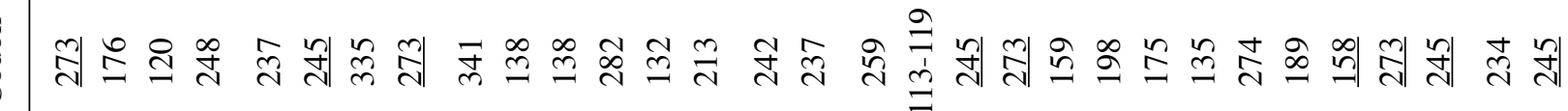

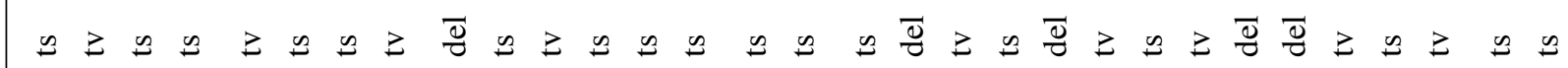

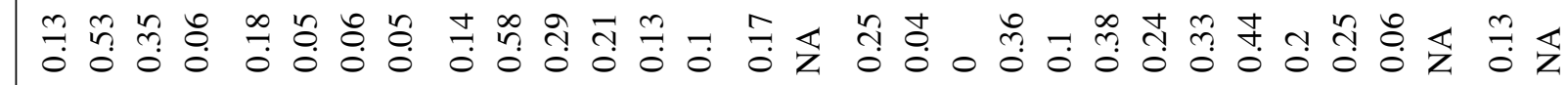

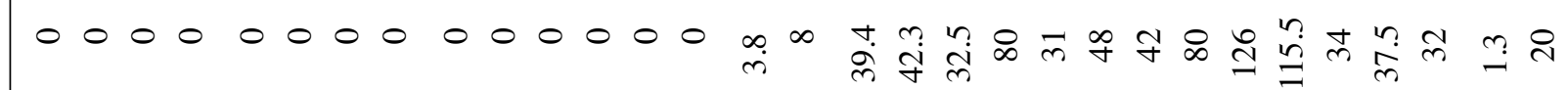

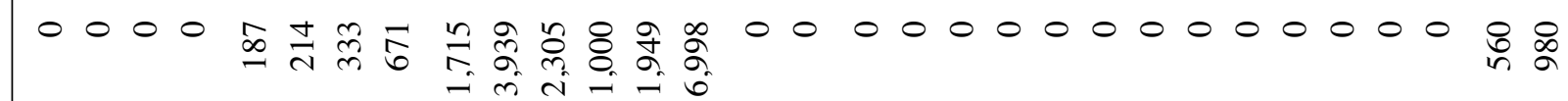

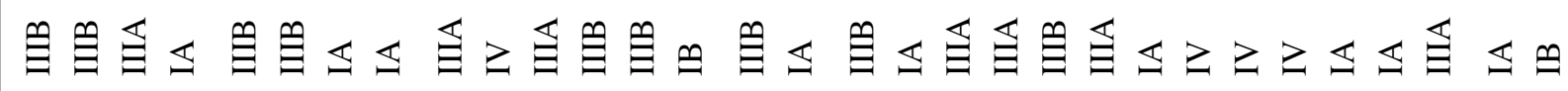
药 死

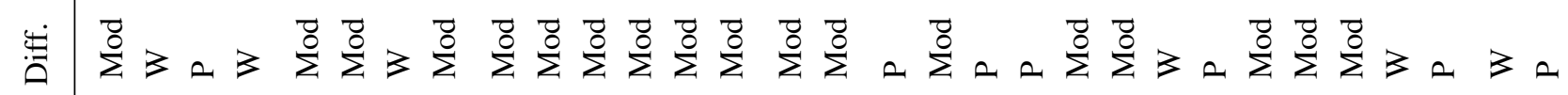

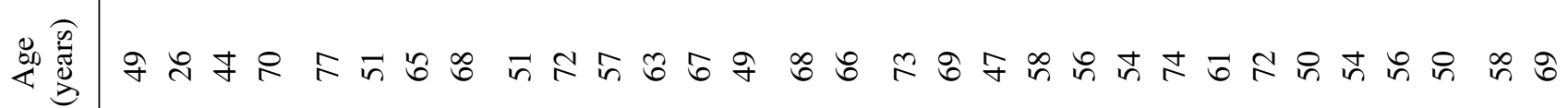

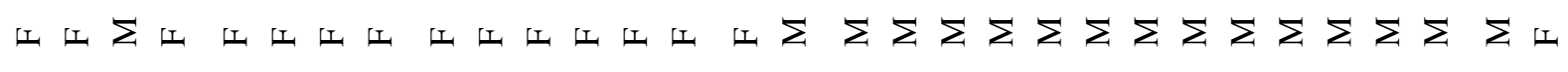
岕 


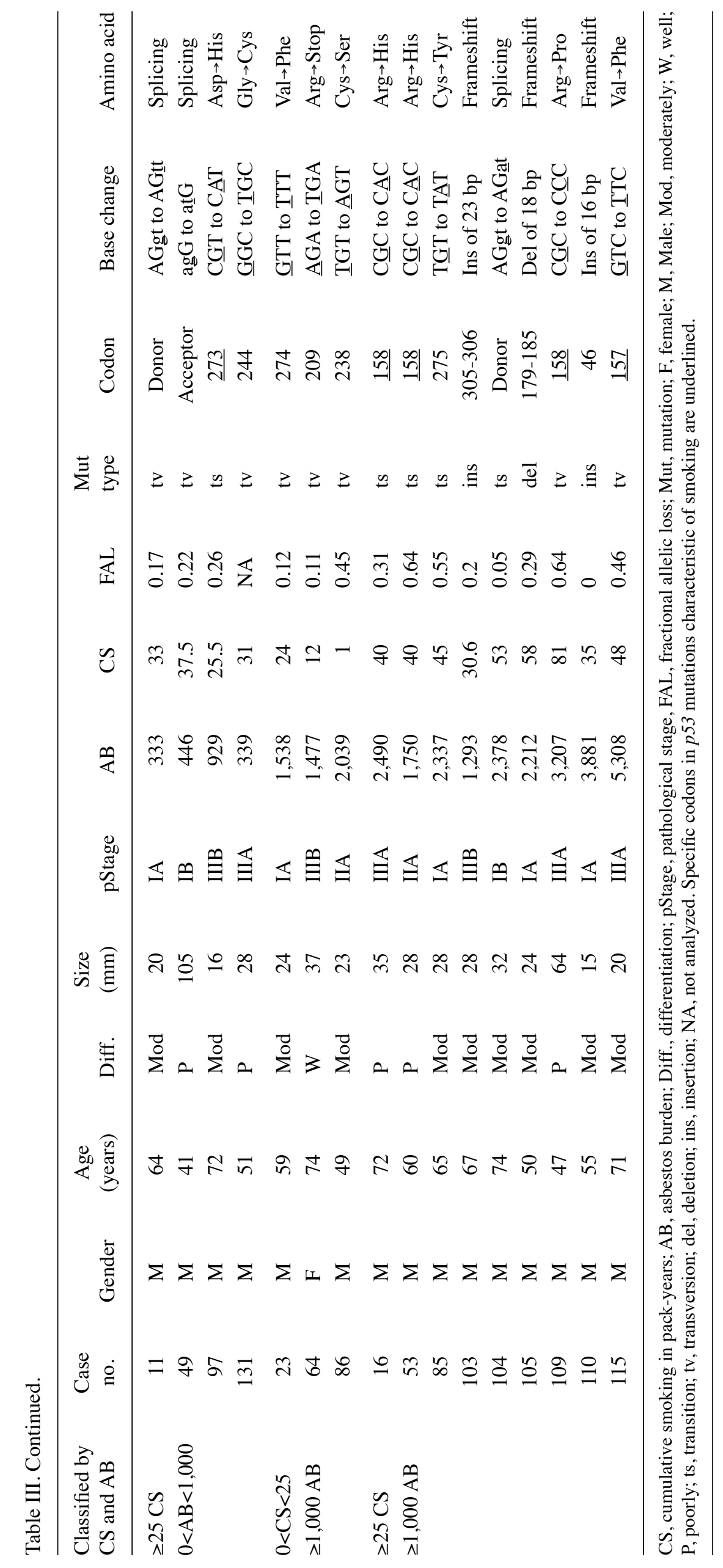


Table IV. p53 mutational spectra in lung adenocarcinomas, classified by AB and CS in pack-years.

\begin{tabular}{|c|c|c|c|c|c|c|c|c|c|c|c|c|}
\hline \multirow[b]{2}{*}{$\begin{array}{l}\text { Classified by } \\
\mathrm{CS} \text { and } \mathrm{AB}\end{array}$} & \multirow[b]{2}{*}{ No. } & \multirow[b]{2}{*}{$\begin{array}{l}\text { With } p 53 \\
\text { mutation } \\
(\%)\end{array}$} & \multicolumn{4}{|c|}{ Transition } & \multicolumn{5}{|c|}{ Transversion } & \multirow[b]{2}{*}{$\begin{array}{c}\text { Del/Ins } \\
(\%)\end{array}$} \\
\hline & & & $\begin{array}{c}\text { CpG } \\
\mathrm{G}: \mathrm{C} \\
\text { to } \\
\mathrm{A}: \mathrm{T}\end{array}$ & $\begin{array}{c}\text { Non-CpG } \\
\text { G:C } \\
\text { to } \\
\text { A:T }\end{array}$ & $\begin{array}{l}\text { A:T } \\
\text { to } \\
\text { G:C }\end{array}$ & $\begin{array}{l}\text { Total } \\
(\%)\end{array}$ & $\begin{array}{c}\mathrm{G}: \mathrm{C} \\
\text { to } \\
\mathrm{T}: \mathrm{A}\end{array}$ & $\begin{array}{l}\mathrm{G}: \mathrm{C} \\
\text { to } \\
\mathrm{C}: \mathrm{G}\end{array}$ & $\begin{array}{c}\text { A:T } \\
\text { to } \\
\text { T:A }\end{array}$ & $\begin{array}{c}\text { A:T } \\
\text { to } \\
\mathrm{C}: \mathrm{G}\end{array}$ & $\begin{array}{c}\text { Total } \\
(\%)\end{array}$ & \\
\hline All cases & 123 & $47(38)$ & 13 & 6 & 3 & $22(47)$ & 13 & 2 & 2 & 0 & $17(36)$ & $8(17)$ \\
\hline $\mathrm{CS}=0$ & 49 & $14(28)$ & 6 & 1 & 2 & $9(64)$ & 3 & 1 & 0 & 0 & $4(29)$ & $1(7)$ \\
\hline $\mathrm{AB}=0$ & 22 & $4(18)$ & 2 & 0 & 1 & $3(75)$ & 1 & 0 & 0 & 0 & $1(25)$ & $0(0)$ \\
\hline $0<\mathrm{AB}<1,000$ & 13 & $4(31)$ & 2 & 0 & 0 & $2(50)$ & 2 & 0 & 0 & 0 & $2(50)$ & $0(0)$ \\
\hline$\geq 1,000 \mathrm{AB}$ & 14 & $6(43)$ & 2 & 1 & 1 & $4(67)$ & 0 & 1 & 0 & 0 & $1(17)$ & $1(17)$ \\
\hline $0<\mathrm{CS}<25$ & 17 & $7(41)$ & 1 & 2 & 1 & $4(57)$ & 1 & 0 & 2 & 0 & $3(43)$ & $0(0)$ \\
\hline $\mathrm{AB}=0$ & 6 & $2(33)$ & 0 & 2 & 0 & $2(100)$ & 0 & 0 & 0 & 0 & $0(0)$ & $0(0)$ \\
\hline $0<\mathrm{AB}<1,000$ & 3 & $2(67)$ & 1 & 0 & 1 & $2(100)$ & 0 & 0 & 0 & 0 & $0(0)$ & $0(0)$ \\
\hline$\geq 1,000 \mathrm{AB}$ & 8 & $3(38)$ & 0 & 0 & 0 & $0(0)$ & 1 & 0 & 2 & 0 & $3(100)$ & $0(0)$ \\
\hline$\geq 25 \mathrm{CS}$ & 57 & $26(46)$ & 6 & 3 & 0 & $9(35)$ & 9 & 1 & 0 & 0 & $10(38)$ & $7(27)$ \\
\hline $\mathrm{AB}=0$ & 33 & $13(39)$ & 3 & 1 & 0 & $4(31)$ & 5 & 0 & 0 & 0 & $5(38)$ & $4(31)$ \\
\hline $0<\mathrm{AB}<1,000$ & 7 & $4(57)$ & 1 & 0 & 0 & $1(25)$ & 3 & 0 & 0 & 0 & $3(75)$ & $0(0)$ \\
\hline$\geq 1,000 \mathrm{AB}$ & 17 & $9(53)$ & 2 & 2 & 0 & $4(44)$ & 1 & 1 & 0 & 0 & $2(22)$ & $3(33)$ \\
\hline
\end{tabular}

Percentages may not total 100, due to rounding. Del/Ins, deletion/insertion; AB, asbestos burden; CS, cumulative smoking.

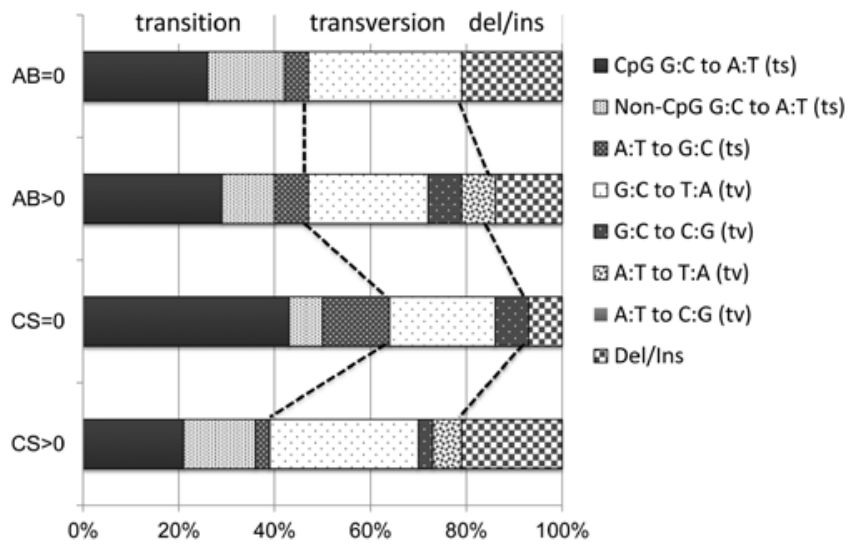

Figure 2. p53 mutation spectra in lung adenocarcinomas. $A B=0(n=19)$ : lung adenocarcinomas from patients without $\mathrm{AB}(0<\mathrm{CS}, \mathrm{n}=15 ; \mathrm{CS}=0, \mathrm{n}=4) . \mathrm{AB}>0$ $(n=28)$ : lung adenocarcinomas from patients with $A B(0<C S, n=18 ; C S=0$, $\mathrm{n}=10) . \mathrm{CS}=0(\mathrm{n}=14)$ : lung adenocarcinomas from non-smokers $(0<A B, \mathrm{n}=10$; $A B=0, n=4)$. $C S>0 \quad(n=33)$ : lung adenocarcinomas from smokers and exsmokers $(0<A B, n=18 ; A B=0, n=15)$. $C S$, cumulative smoking in pack-years; $\mathrm{AB}$, asbestos burden; ts, transition; tv, transversion; Del/Ins, deletion/insertion.

tobacco-specific codons were frequently observed in the $\mathrm{CS}>0$ groups, whereas non-specific mutations were often detected in the $\mathrm{CS}=0, \mathrm{AB}>0$ groups (Tables III and IV). In the $\geq 1,000 \mathrm{AB}$, $\mathrm{CS}=0$ group, there was only one transversion and no tobaccospecific codons for the six p53 mutations. In contrast, in the $\mathrm{AB}=0, \geq 25 \mathrm{CS}$ group, there were five $\mathrm{G}: \mathrm{C}$ to $\mathrm{T}: \mathrm{A}$ transversions and five tobacco-specific codons among 13 p53 mutations. Fig. 2 shows p53 mutation spectra in lung adenocarcinomas, classified as smokers $(\mathrm{A}, \mathrm{n}=33)$ or non-smokers $(\mathrm{B}, \mathrm{n}=14)$ and asbestos-exposed $(\mathrm{C}, \mathrm{n}=28)$ or not $(\mathrm{D}, \mathrm{n}=19)$. Although p53 mutation spectra varied depending on the status of smoking history, they showed little difference between asbestosexposed or non-exposed. Whereas smokers had frequent G:C to T:A transversions, which are smoking-associated p53 mutations, non-smokers had frequent $\mathrm{G}: \mathrm{C}$ to $\mathrm{A}: \mathrm{T}$ transitions at $\mathrm{CpG}$ sites associated with spontaneous mutations, consistent with previous reports $(9,17)$.

With respect to tumor differentiation grade, a heavier smoking habit was associated with less-differentiated adenocarcinomas (Fig. 3A, p=0.0010, Chi-square test), in line with a previous study (18). On the other hand, there was no correlation between asbestos deposition and the differentiation grade (Fig. 3B, $\mathrm{p}=0.75$ ).

\section{Discussion}

Both tobacco smoke and asbestos fibers are significant inhaled carcinogens which contribute significantly to lung adenocarcinoma development. We previously revealed that chromosome instability and $\mathrm{LOH}$, rather than minisatellite and microsatellite instability, play major roles in the development of lung adenocarcinomas (19). The LOH and $p 53$ spectra provide clues concerning the etiology and nature of carcinogenesis. To elucidate the carcinogenic mechanisms of two different inhaled carcinogens, asbestos and cigarette smoke, we investigated $\mathrm{LOH}$ on all autosomal chromosomes and measured asbestos burden (AB; asbestos body per gram of dry lung tissue) using corresponding normal lung tissue and investigated p53 mutation employing fresh tumor samples.

The p53 mutational spectra may be helpful for identification of the origins of the mutations that give rise to human 
A

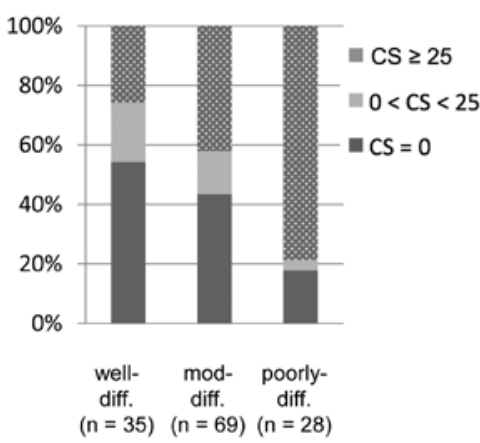

B

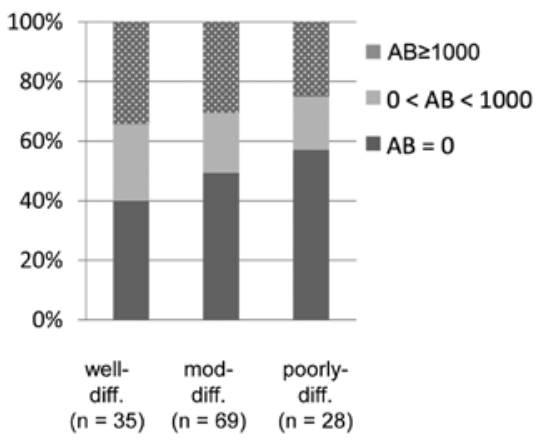

Figure 3. Cumulative smoking (CS) in pack-years (A) and asbestos burden (AB) (B) with reference to the histological differentiation grade. Although there was a significant relationship between $\mathrm{CS}$ and the differentiation grade $(\mathrm{p}=0.0010$, Chi-square test), there was no correlation between $\mathrm{AB}$ and the differentiation grade $(\mathrm{p}=0.75)$. Well-diff., well-differentiated; mod-diff., moderately differentiated; poorly-diff., poorly differentiated.

cancers. For example, aflatoxin B1-associated hepatocellular carcinomas frequently have the specific $p 53$ mutations: $\mathrm{G}: \mathrm{C}$ to T:A transversions at the 3rd base of codon 249, AGG to AGT (Arg to Ser) (20). Another example of a clearly characteristic 'finger-print' mutation in $p 53$ is the $\mathrm{CC}$ to TT double mutation in skin cancer (21). Exposure to UV light, a physical mutagen, produces distinctive pyrimidine dimers that, if unrepaired, can produce tandem mutations, most characteristically CC to TT transitions. Similar to these, the p53 mutational spectra can provide clues to the etiology of cancers.

The possible role of asbestos-exposure in the genesis of p53 mutations in lung cancers is less well understood. Husgafvel-Pursiainen et al investigated p53 mutation of 105 lung cancers from smokers, comprising 53 squamous cell carcinomas, 39 adenocarcinomas and other 13 carcinomas, focusing on the presence or absence of asbestos-exposure (22). They found p 53 mutations in $39 \%$ of asbestos-exposed patients with lung cancer while the percentage was $54 \%$ in patients not exposed to asbestos, indicating that the p53 mutations were less common among the cases with occupational asbestosexposure than in the non-exposed cases. These results have not been verified yet by another study, and need additional examinations of smoking status.

In adenocarcinoma without asbestos-exposure or smokingexposure, the $p 53$ mutation rate was the lowest. It increased in correlation with the elevation of asbestos-exposure and/ or smoking-exposure. Adenocarcinomas associated with frequent smoking have characteristic p53 mutations, especially G:C to T:A transversions (17), at specific 'hotspot' codons (13). However, adenocarcinomas associated only with asbestos-exposure had non-specific p53 mutations, such as transitions which are thought to be caused by endogenous mechanisms associated with spontaneous events $(9,17)$. Asbestos may work in a promoter-like manner. Production of reactive oxygen species and/or induction of tissue regeneration may be relevant.

Adenocarcinomas have different etiologies from squamous cell carcinomas, which can be reflected also in terms of $\mathrm{LOH}$. As we revealed, LOH frequency was higher in squamous cell carcinomas than in adenocarcinomas $(6,7)$. Poorly differentiated adenocarcinomas, which are often noted in smokers such as squamous cell carcinomas, have higher $\mathrm{LOH}$ frequency than differentiated adenocarcinomas, which have a relatively weaker association with smoking (23). Smoking induces complicated genetic changes in lung cancers.

One of the most intriguing recent discoveries in the field of lung cancer research is the identification of new driver mutations in lung adenocarcinomas, such as EGFR mutations $(24,25)$ and $A L K$ fusion (26). Both lung cancers with $E G F R$ mutations or $A L K$ translocations are characterized by negative or light smoking history. Lung cancers in non-smokers are considered to be less genetically complex than those in smokers and therefore they often have distinct characteristics developing on simple gene mutations for maintenance and survival. Consequently, patients with tumors harboring such simple oncogenic mutations represent good candidates who may stand to benefit from molecular-targeted drugs. To date, two-thirds of Japanese adenocarcinomas and a little more than half of Caucasian adenocarcinomas have mutually exclusive oncogenic mutations or other genetic alterations including EGFR, KRAS, MET, ALK and HER2 (27). Asbestos-associated alterations in chromosomal regions, such as 19p13 (28), 9q33.1 (29) and 2p16 (30) have been identified. Whereas the smoking status has a significant association with driver mutations in lung adenocarcinomas, the relationship with asbestos-exposure remains unclear.

In adenocarcinomas without asbestos-exposure, the LOH frequency increased only slightly, correlating with the elevation in smoking-exposure. On the other hand, in adenocarcinomas with asbestos-exposure, the $\mathrm{LOH}$ frequency increased as asbestos-exposure and/or smoking-exposure was elevated. This suggests that asbestos-exposure in concert with smoking-exposure increases LOH frequency.

In the present study, lung adenocarcinomas, for which asbestos-exposure and smoking-exposure data could be obtained, were examined for $\mathrm{LOH}$ and the $p 53$ mutation. Combined effects of asbestos and cigarette smoke were suggested by these analyses. Asbestos-exposure alone did not increase the $\mathrm{LOH}$ frequency but increased non-specific $p 53$ mutations. These findings suggest that the major carcinogenic mechanism of asbestos in lung adenocarcinomas may be as a promoter, contributing to the genotoxic effect of cigarette smoke. Since this study was based on a general cancer center's experience, the limited sample size does not permit consider- 
ation that the result is conclusive. Further investigation with a large sample size is required to establish the mechanism of asbestos-induced lung carcinogenesis.

\section{Acknowledgements}

The authors thank Ms. Miyuki Kogure,Mr. Motoyoshi Iwakoshi, Ms. Tomoyo Kakita, and Ms. Shizue Kurimori for their technical assistance, and Ms. Yuki Takano and Ms. Yumiko Toriyama for secretarial assistance. Parts of this study were supported financially by Grants-in-Aid for Scientific Research from the Ministry of Education, Culture, Sports, Science and Technology, from the Japan Society for the Promotion of Science including Grant-in-Aid for Young Scientists (B), and by grants from the Ministry of Health, Labour and Welfare, the Smoking Research Foundation, and the Vehicle Racing Commemorative Foundation.

\section{References}

1. LaDou J: The asbestos cancer epidemic. Environ Health Perspect 112: 285-290, 2004.

2. Jaurand MC: Mechanisms of fiber-induced genotoxicity. Environ Health Perspect 105 (Suppl 5): 1073-1084, 1997.

3. Heintz NH, Janssen YM and Mossman BT: Persistent induction of c-fos and c-jun expression by asbestos. Proc Natl Acad Sci USA 90: 3299-3303, 1993.

4. Timblin CR, Janssen YW and Mossman BT: Transcriptional activation of the proto-oncogene c-jun by asbestos and $\mathrm{H}_{2} \mathrm{O}_{2}$ is directly related to increased proliferation and transformation of tracheal epithelial cells. Cancer Res 55: 2723-2726, 1995.

5. Doll R: Mortality from lung cancer in asbestos workers. Br J Ind Med 12: 81-86, 1955.

6. Tsuchiya E, Nakamura Y, Weng SY, et al: Allelotype of non-small cell lung carcinoma - comparison between loss of heterozygosity in squamous cell carcinoma and adenocarcinoma. Cancer Res 52: 2478-2481, 1992.

7. Sato S, Nakamura Y and Tsuchiya E: Difference of allelotype between squamous cell carcinoma and adenocarcinoma of the lung. Cancer Res 54: 5652-5655, 1994.

8. Hashimoto T, Tokuchi Y, Hayashi M, et al: Different subtypes of human lung adenocarcinoma caused by different etiological factors. Evidence from p53 mutational spectra. Am J Pathol 157: 2133-2141, 2000

9. Hollstein M, Sidransky D, Vogelstein B and Harris CC: p53 mutations in human cancers. Science 253: 49-53, 1991.

10. Vähäkangas K: TP53 mutations in workers exposed to occupational carcinogens. Hum Mutat 21: 240-251, 2003.

11. Petitjean A, Mathe E, Kato S, et al: Impact of mutant p53 functional properties on TP53 mutation patterns and tumor phenotype: lessons from recent developments in the IARC TP53 database. Hum Mutat 28: 622-629, 2007.

12. Denissenko MF, Pao A, Tang M and Pfeifer GP: Preferential formation of benzo $[a]$ pyrene adducts at lung cancer mutational hotspots in P53. Science 274: 430-432, 1996.

13. Smith LE, Denissenko MF, Bennett WP, et al: Targeting of lung cancer mutational hotspots by polycyclic aromatic hydrocarbons. J Natl Cancer Inst 92: 803-811, 2000.
14. Japan Lung Cancer Society: General Rules for Clinical and Pathologic Record of Lung Cancer. 5th edition. Kanahara, Tokyo, 1999 (In Japanese).

15. Inamura K, Satoh Y, Okumura S, et al: Pulmonary adenocarcinomas with enteric differentiation: histologic and immunohistochemical characteristics compared with metastatic colorectal cancers and usual pulmonary adenocarcinomas. Am J Surg Pathol 29: 660-665, 2005.

16. Kohyama N and Suzuki Y: Analysis of asbestos fibers in lung parenchyma, pleural plaques, and mesothelioma tissues of North American insulation workers. Ann NY Acad Sci 643: 27-52, 1991.

17. Greenblatt MS, Bennett WP, Hollstein M and Harris CC: Mutations in the $p 53$ tumor suppressor gene: clues to cancer etiology and molecular pathogenesis. Cancer Res 54: 4855-4878, 1994.

18. Nakachi K, Hayashi S, Kawajiri K and Imai K: Association of cigarette smoking and $C Y P 1 A 1$ polymorphisms with adenocarcinoma of the lung by grades of differentiation. Carcinogenesis 16: 2209-2213, 1995 .

19. Ninomiya $H$, Nomura $K$, Satoh Y, et al: Genetic instability in lung cancer: concurrent analysis of chromosomal, mini- and microsatellite instability and loss of heterozygosity. Br J Cancer 94: 1485-1491, 2006

20. Hsu IC, Metcalf RA, Sun T, Welsh JA, Wang NJ and Harris CC: Mutational hotspot in the p53 gene in human hepatocellular carcinomas. Nature 350: 427-428, 1991.

21. Brash DE, Rudolph JA, Simon JA, et al: A role for sunlight in skin cancer: UV-induced p53 mutations in squamous cell carcinoma. Proc Natl Acad Sci USA 88: 10124-10128, 1991.

22. Husgafvel-Pursiainen K, Karjalainen A, Kannio A, et al: Lung cancer and past occupational exposure to asbestos. Role of $p 53$ and $\mathrm{K}$-ras mutations. Am J Respir Cell Mol Biol 20: 667-674, 1999.

23. Ishikawa Y,Furuta R, Miyoshi T, et al: Loss of heterozygosity and the smoking index increase with decrease in differentiation of lung adenocarcinomas: etiologic implications. Cancer Lett 187: 47-51, 2002.

24. Lynch TJ, Bell DW, Sordella R, et al: Activating mutations in the epidermal growth factor receptor underlying responsiveness of non-small-cell lung cancer to gefitinib. N Engl J Med 350: 2129-2139, 2004.

25. Paez JG, Jänne PA, Lee JC, et al: EGFR mutations in lung cancer: correlation with clinical response to gefitinib therapy. Science 304: 1497-1500, 2004.

26. Soda M, Choi YL, Enomoto M, et al: Identification of the transforming $E M L 4-A L K$ fusion gene in non-small-cell lung cancer. Nature 448: 561-566, 2007.

27. Inamura $\mathrm{K}$ and Ishikawa $\mathrm{Y}$ : Lung Cancer. Asian Pacific Organization for Cancer Prevention Cancer Report 2010. Tuncer MA (ed). New Hope in Health Foundation, Turkey, pp202-204, 2010.

28. Ruosaari ST, Nymark PE, Aavikko MM, et al: Aberrations of chromosome 19 in asbestos-associated lung cancer and in asbestos-induced micronuclei of bronchial epithelial cells in vitro. Carcinogenesis 29: 913-917, 2008.

29. Nymark P, Kettunen E, Aavikko M, et al: Molecular alterations at 9q33.1 and polyploidy in asbestos-related lung cancer. Clin Cancer Res 15: 468-475, 2009.

30. Kettunen E, Aavikko M, Nymark P, et al: DNA copy number loss and allelic imbalance at 2p16 in lung cancer associated with asbestos exposure. Br J Cancer 100: 1336-1342, 2009. 